\title{
Identificación de nuevos peces ornamentales fluorescentes transgénicos introducidos al territorio peruano: a casi una década de la moratoria de OVMs
}

Identification of new transgenic fluorescent ornamental fish introduced to the Peruvian territory: almost one decade after the moratorium of OVMs

Recibido: febrero 10 de 2018 | Revisado: marzo 18 de 2018 | Aceptado: mayo 22 de 2018

\section{Carlos Scotto Espinoza ${ }^{\mathrm{I}}$ \\ Ricardo Chuan García ${ }^{\mathrm{I}}$ Génesis Pajares Cárdenas ${ }^{\mathrm{I}}$}

\begin{abstract}
RESUMEN
Este año 2018, se reporta la presencia de dos nuevas especies de peces ornamentales fluorescentes y sus líneas. Se trata de los peces Monjita [Gymnocorymbus ternetzi, Boulenger (1895)] y el pez Barbo sumatrano [Puntius tetrazona, Bleeker (1855)] dentro del territorio peruano. Se identificó su fluorescencia por exposición ante la luz UV a 400nm. Se comparó con la fluorescencia de peces Cebra fluorescentes transgénicos $(D a-$ nio rerio) identificados molecularmente, con anterioridad, por poseer el transgén RFP de color rojo $(\mathrm{RFP}=$ Red Fluorescente Protein) y el transgén de color verde $(\mathrm{GFP}=$ Green Fluorescent Protein) junto con los controles negativos de los peces Cebra sin los transgenes GFP y RFP; del mismo modo, con los controles negativos respectivos de los peces Monjita y Barbo. Se logró identificar nuevas variantes de colores fluorescentes en el pez Monjita, esto es, los colores morado, naranja, amarillo y azul; y, en el pez Barbo sumatrano, solamente se han identificado los colores verde y rojo.
\end{abstract}

Palabras clave: Gymnocorymbus ternetzi, Puntius tetrazona, Danio rerio, fluorescencia, transgén

\begin{abstract}
Nowadays, in this year of 2018, the presence of two new species of fluorescent ornamental fish and their lines is reported. These are the fish named Monjita [Gymnocorymbus ternetzi, Boulenger (1895)] and the fish named Sumatran Barbo [Puntius tetrazona, Bleeker (1855)] within the Peruvian territory. Its fluorescence was identified by exposure to UV light at $400 \mathrm{~nm}$. It was compared with the fluorescence of fluorescent transgenic Zebra fish (Danio rerio) identified molecularly, previously, by having the red RFP transgene $(\mathrm{RFP}=\mathrm{Red}$ Fluorescent Protein) and the green color transgene (GFP = Green Fluorescent Protein) together with the negative controls of the Zebra fish without the GFP and RFP transgenes; in the same way, with the respective negative controls of the Monjita and Barbo fish. It was possible to identify new variants of fluorescent colors in the Monjita fish, that is, the colors purple, orange, yellow and blue; and, in case of the Sumatran Barbo, only the green and red colors have been identified.
\end{abstract}

Key words: Gymnocorymbus ternetzi, Puntius tetrazon, Danio rerio, fluorescence, transgen
Universidad Nacional Federico Villarreal, Lima, Perú

carlosscottoespinoza@gmail.com

18.v23n25.07

| Campus | Lima, perú | V. XXIII | N. 25 | PP. 89-94 | ENERO-JUNIO | 2018 | ISSN I8I2-6049 


\section{Introducción}

Entre los grupos de peces ornamentales fluorescentes más cotizados a nivel mundial se encuentran los peces Monjitas (Gymnocorymbus ternetzi), el Barbo sumatrano (Puntius tetrazona) y el pez Cebra (Danio rerio) (GBIF Backbone Taxonomy Checklist dataset, 2018). Estos peces se encuentran distribuidos por todo el mundo, y destacan por su belleza y brillante colorido en los acuarios o "Pet shop" que los reproducen y venden. Diversos países asiáticos y USA han logrado reproducir exitosamente hasta la tercera generación (F3) diferentes variedades o líneas genéticas estables de estos peces ornamentales transgénicos (Noticias de Taiwan, 2015; Wan et al., 2002).

Actualmente, los peces ornamentales transgénicos más comercializados son el pez Ángel o escalar (Pterophyllum scalare, Schultze, 1823); el cíclido convicto (Amatitlania nigrofasciata, Günther, 1867); el pez Cebra (Danio rerio, Hamilton, 1822); el Monjita o Tetra (Gymnocorymbus ternetzi, Boulenger, 1895); el Barbo sumatrano (Puntius tetrazona, Bleeker, 1855); el Medaka (Oryzias latipes, Temminck y Schlegel, 1846); el Neón chino (Tanichthys albonubes, Lin, 1932) entre otros (Bielikova, 2012; Pan et al., 2008; Qing et al., 2012; Zhu, 1992).

El pez Monjita o Tetra (Gymnocorymbus ternetzi), pertenece a la Familia Characidae (Boulenger, 1895). Es una especie nativa de la cuenca Amazónica y del Orinoco (Uma \& Chandran, 2009). Llega a medir $5,5 \mathrm{~cm}$. Y vive a temperaturas óptimas de 20 a $26^{\circ} \mathrm{C}$. Es una especie muy prolífera y fácil de reproducir (Aquanovel, 2017).
El Barbo sumatrano o Tigre (Puntius tetrazona) pertenece a la Familia Cyprinidae (Bleeker, 1855). Es un pez tropical nativo de la península Malaya,y de las islas de Sumatra (Indonesia) y Borneo (Malasia), así como algunas zonas de Tailandia. Son especies muy adaptables y robustas que podemos mantener perfectamente en aguas duras o blandas, con un $\mathrm{pH}$ entre 6 y 8 . Y vive a temperaturas óptimas entre 22 a 28 grados centígrados (Tamaru et al., 1997).

Se tiene poco conocimiento del posible impacto ambiental sobre el ambiente ante la liberación descontrolada de estos peces transgénicos por la falta de un análisis de riesgos que evalúe su flujo génico (Manzi, 2016). Por lo tanto, el objetivo de este trabajo fue identificar y comparar la fluorescencia de los peces transgénicos Monjita y del Barbo sumatrano y compararla con la fluorescencia roja y verde del pez Cebra transgénico que dieron positivo molecularmente por la presencia de los transgenes GFP y poder generar información para su rápida detección RFP.

\section{Materiales y método}

En el año 2018, se adquirieron peces Monjitas y Barbo sumatrano con diferentes colores fluorescentes y peces de color blancos no fluorescentes vivos obtenidos de diferentes acuarios locales de la ciudad de Lima Metropolitana y fueron llevados al Laboratorio de Mejora Genética y Reproducción Animal de la Facultad de Ciencias Naturales y Matemática de la UNFV para su crianza y manutención. Se utilizó un transiluminador UV de 400 nm de longitud de onda a los cuales fueron expuestos los peces Monjita y Barbo 
sumatrano para evidenciar la presencia de fluorescencia corporal o no. Se utilizó como control positivo al pez Cebra de color rojo y verde fluorescentes, previamente identificados con la presencia de los transgenes de GFP (Color verde) y RFP (Color rojo) con las secuencias de los primers reportados hasta la fecha por Bielikova et al. (2012); Rehbein y Bogerd (2007) y Ofelio et al. (2012) (Tabla 1).

Tabla 1

Secuencias de primers utilizados para identificar peces Cebra transgénicos

\begin{tabular}{|c|c|c|c|c|}
\hline Gen & Nombre & Secuencia (5' - 3') & $\begin{array}{c}\text { Tamaño } \\
\text { en pb }\end{array}$ & Referencia \\
\hline GFP & GFP1F & TCG AGC TGG ACG GCG ACG T & \multirow{2}{*}{570} & \multirow{2}{*}{$\begin{array}{l}\text { Bielikova et al. } \\
\text { (2012) }\end{array}$} \\
\hline GFP & GFP1R & GGT GCT CAG GTA GTG GTT GTC & & \\
\hline RFP & $\begin{array}{c}\text { RFP/ } \\
\text { Rerio2006 } \\
\end{array}$ & ACA ACA CCG TGA AGC TGA AGG TGA CCA AG & \multirow{2}{*}{505} & \multirow{2}{*}{$\begin{array}{l}\text { Rehbein \& Bogerd } \\
\qquad(2007)\end{array}$} \\
\hline RFP & $\begin{array}{c}\text { RFP/ } \\
\text { Rerio2006 } \\
\end{array}$ & GGT GTA GTC CTC GTT GTG GGA GGT GAT GTC & & \\
\hline RFP & 2-RFP_F & GAAGCACCCCGCCGACATCC & \multirow{2}{*}{350} & \multirow{2}{*}{ Ofelio et al. (2012) } \\
\hline RFP & 7-RFP_R & GGCAGCTGCACGGGCTTCTTGGC & & \\
\hline
\end{tabular}

Se utilizó como control negativo al pez Cebra No transgénico de color blanco que dio negativo para ambos primeros (GFP y RFP). Y como control negativo de la fluorescencia de los peces Monjitas y Barbos sumatranos se utilizaron peces de color blanco no fluorescentes para ambas especies.

\section{Resultados y discusión}

Se utilizó como controles probados a nivel de luminosidad fluorescente y a ni- vel de las líneas de los peces de colores verde y rojo reproducidos en el Laboratorio de Mejora Genética y Reproducción Animal, los que fueron expuestos a la luz ultravioleta presentando fluorescencia corporal y confirmándose cualitativamente su transgénesis por la presencia de genes de fluorescencia (GFP y RFP). Como control negativo se utilizaron peces Cebras silvestres blancos no fluorescentes, los cuales no dieron ninguna fluorescencia o coloración con la luz ultravioleta (Figura 1).

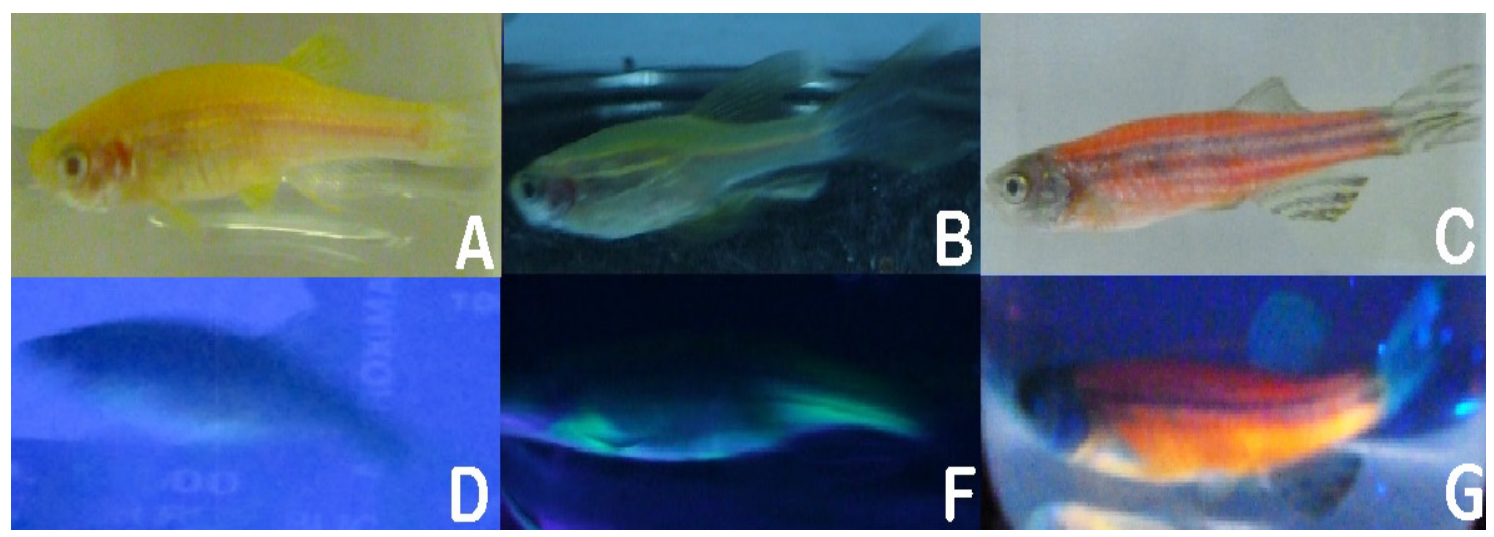

Figura 1. Con luz natural: $\mathrm{A}=$ Pez Cebra No transgénico de color blanco; $\mathrm{B}=$ Pez Cebra transgénico de color verde; $C=$ Pez Cebra transgénico de color rojo. Con luz UV: $D=$ Pez Cebra No transgénico de color blanco; $\mathrm{F}=$ Pez Cebra transgénico de color verde; $\mathrm{F}=$ Pez Cebra transgénico de color rojo. 
Los peces Monjitas de colores verde, morado, naranja, amarillo y azul expuestos a la luz ultravioleta presentaron fluorescencia corporal confirmándose cualitativamente su transgénesis por la presencia de genes de fluorescencia. Como control negativo se utilizaron peces Monjitas silvestres blancos no fluorescentes, los que no dieron ninguna fluorescencia o coloración con la luz ultravioleta (Figura 2).

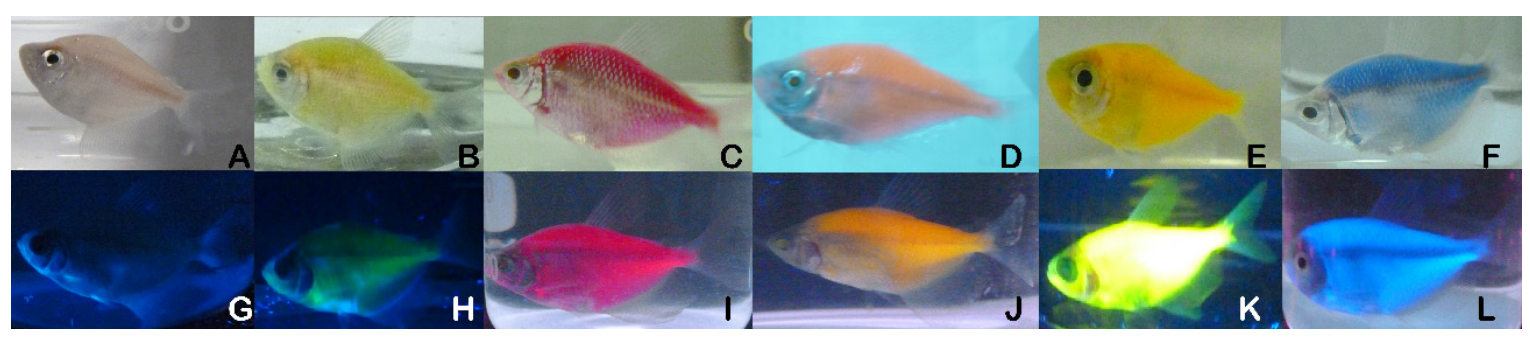

Figura 2. Con luz natural: $A=$ Pez Monjita No transgénico de color blanco; $B=$ Pez Monjita transgénico de color verde; $\mathrm{C}=$ Pez Monjita transgénico de color morado; $\mathrm{D}=$ Pez Monjita transgénico de color naranja; $\mathrm{E}=$ Pez Monjita transgénico de color amarillo; F = Pez Monjita transgénico de color azul. Con luz UV: $\mathrm{G}=$ Pez Monjita No transgénico de color blanco; $\mathrm{H}=$ Pez Monjita transgénico de color verde; I = Pez Monjita transgénico de color morado; $\mathrm{J}=$ Pez Monjita transgénico de color naranja; $\mathrm{K}=$ Pez Monjita transgénico de color amarillo; $\mathrm{L}=\mathrm{Pez}$ Monjita transgénico de color azul.

Los peces Barbos sumatranos de colores verde y rojo expuestos a la luz ultravioleta presentaron fluorescencia corporal confirmándose cualitativamente su transgénesis por la presencia de genes de fluorescencia. Como control negativo se utilizaron peces Barbos sumatranos silvestres blancos no fluorescente, los que no dieron ninguna fluorescencia o coloración con la luz ultravioleta (Figura 3).

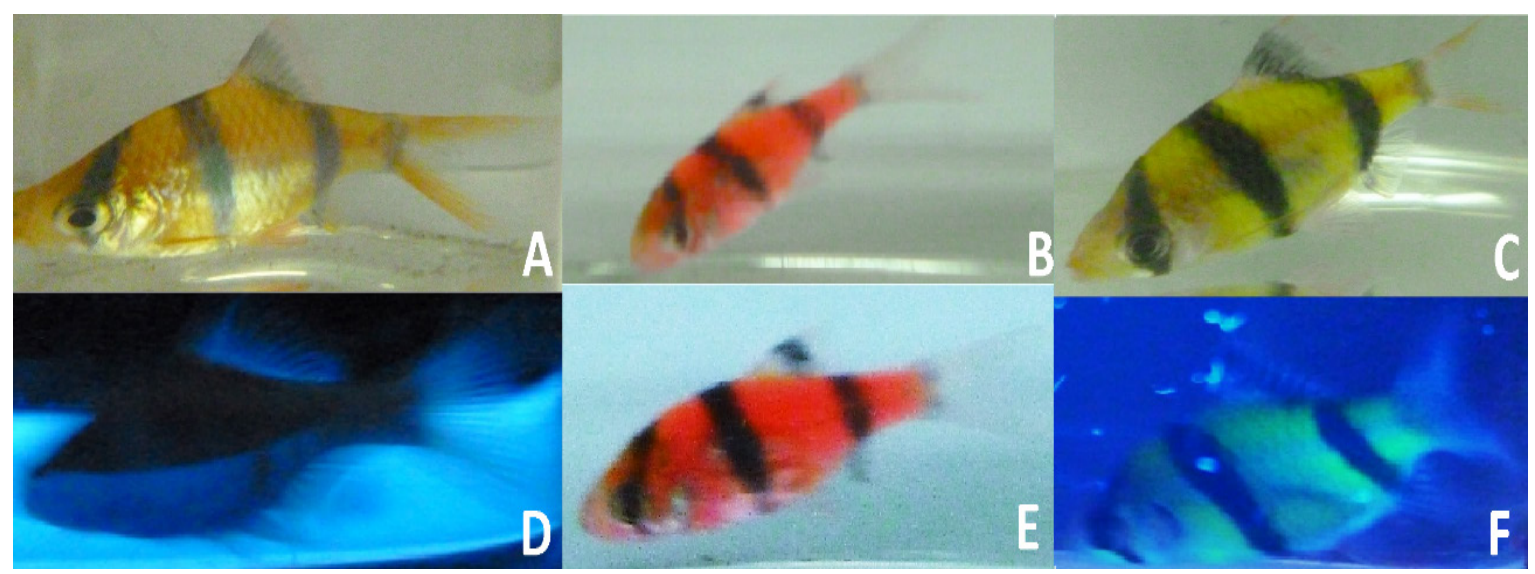

Figura 3. Con luz natural: $\mathrm{A}=$ Pez Barbo No transgénico de color blanco; $\mathrm{B}=$ Pez Barbo transgénico de color rojo; $\mathrm{C}=$ Pez Barbo transgénico de color verde. Con luz UV: $\mathrm{D}=$ Pez Barbo No transgénico de color blanco; $\mathrm{E}=$ Pez Barbo transgénico de color rojo; $\mathrm{F}=$ Pez Barbo transgénico de color verde.

\section{Conclusiones}

Se comprueba la existencia de una nueva especie de peces transgénicos introducidos a territorio peruano como son los peces Barbo sumatrano (Puntius tetrazona). Y se evidenció la presencia de más colores fluorescentes de peces Monjitas (Gymnocorymbus ternetzi) reportado por Scotto desde el año 2004 y su pos- 
terior identificación molecular (Scotto \& Serna, 2013; Svcotto, 2018). Todos mostraron la misma fluorescencia corporal al igual que el pez Cebra (Danio rerio) al ser expuestos a la luz UV. Asimismo, los controles negativos no presentaron fluorescencia no evidenciándose este rasgo transgénico igual que en el control negativo de los peces Cebra, previamente analizado.

Por otro lado, en el pez Barbo Sumatrano se identificaron los mismos colores rojo y verde fluorescentes existentes en el pez Cebra. Mientras que en el pez Monjita se identificó otros colores fluorescentes adicionales como fueron el morado, naranja, amarillo y el azul.
Un aspecto importante a considerarse es que a nivel molecular los primers comerciales existente de GFP y RFP, útiles para identificar al pez Cebra fluorescente transgénico (Tabla 1). No es efectiva para identificar molecularmente al pez Monjita $y$ al Barbo sumatrano que dieron negativo para los primeros de GFP y RFP utilizados para identificar molecularmente a los peces Cebra. Debido, probablemente a que posee variantes en la secuencia nucleotídica que deberán ser estandarizados para generar protocolos adecuados para su identificación molecular a nivel de laboratorio de ambas especies y poder robustecer el control de ingreso y control de los mismos al Perú al existir una ley de moratoria hasta el año 2021 (Ley No 29811, 2011).

\section{Referencias}

Aquanovel (Revista y comercio online). 2017. Recuperado de: http://aquanovel.com/index.htm

Bielikova, M.; Bukovska, G.; Vavrova, S.; Timko, J. \& Turna, J. 2012. Identificación de pez Cebra (Danio rerio) genéticamente modificado por métodos de PCR. En: http:// gmoglobalconference.jrc.ec.europa.eu/ Posters.htm leído el 20 de noviembre de 2015.

GBIF Backbone Taxonomy. Checklist dataset. 2018. Recuperado de: https://doi.org/10.15468/39omei

Ley que establece la moratoria al ingreso y producción de organismos vivos modificados al territorio nacional por un período de 10 ańos (Ley No 29811, 2011, Diciembre 09). Dia- rio Oficial El Peruano, pp. 454601. En: http://minagri.gob.pe/portal/ download/pdf/marcolegal/ normas legales/leyes/ ley29811_ley_prod_ organismos_vivos.pdf leído 20 de noviembre de 2015.

Manzi, María Cristina (2016). ¿Por qué producir peces transgénicos? Beneficios y riesgos. Tesis para optar el grado de Doctor. Universidad de la Republica, Facultad de Veterinaria. Montevideo, Uruguay. 84pp.

Noticias de Taiwan. República de China (Taiwan). 30 de Junio del 2015. Peces fluorescentes obtenidos con ingeniería genética. Recuperado de: https:// noticias.nat. gov.tw/news.php? un i$\mathrm{t}=95,106,115 \&$ post $=87705$ 
Ofelio, C., Cariani, A., Trentini, M. \& Guarniero, I. 2012. Novel PCR-based assay for rapid identification of Red Fluorescent Proteins in GloFish and GloFish x wildtype zebrafish (Danio rerio) hybrids. Italian Journal of Zoology, 79:4, 541-546.

Pan, X., Zhan, H. \& Gong, Z. 2008. Ornamental Expression of Red Fluorescent Protein in Transgenic Founders of White Skirt Tetra (Gymnocorymbus ternetzi). Marine Biotechnology, 10:497-501.

Qing, J., Chen, M., Bai, D., Jiang, P., Fan, J., Ye, X. \& Xia, S. 2012. Generation and characterization of a stable red fluorescent transgenic Tanichthys albonubes line. African Journal of Biotechnology, 11: 77567765.

Rehbein, H.; Bogerd, J. 2007. Identification of Genetically Modified Zebrafish (Danio rerio) by Proteinand DNA-Analysis. Journal fur Verbracherschutz und Lebensmittelsicherheit. 2: 122-125.

Scotto, C. \& Serna, F. 2013. Primera identificación molecular del transgén de la proteína fluorescente roja (RFP) en peces Cebra (Danio rerio) transgénicos ornamentales introducidos en el Perú. Scientia Agropecuaria, 4: 257-264.
Scotto, Carlos. 2018. Nota Científica: Reporte de una segunda introducción de peces ornamentales transgénicos fluorescentes al territorio peruano: Caso pez monjita (Gymnocorymbus ternetzi; Boulenger, 1895). Scientia Agropecuaria. Vol. 9(1):153-156.

Tamaru, C., Cole, B., Bayley, R. \& Brown, C. 1997. A manual for the commercial production of the Tiger barb, Capoeta tetrazona, a temporary paired tank spawner. Center for Tropical and Subtropical Aquaculture publication. (129):50.

Uma, B. \& Chandran, M. (2009) First report on the karyology of Gymnocorymbus ternetzi (Boulenger). Research Journal of Cell and Molecular Biology, 3, 113-115

Wan, H., He, J., Ju, B., Yan, T., Lam, T.J., \& Gong, Z. 2002. Generation of Two-color Transgenic Zebrafish Using the Green and Red Fluorescent Protein Reporter Genes GFP and RFP. Marine Biotechnology, 4:146-54.

Zhu, Z. 1992. Generation of fast growing transgenic fish: Methods and mechanisms. In Transgenic Fish. Hew, C. L. \& Fletcher, G. L. (eds.) Singapore, Singapore World Scientific, pp. 92-119. 
CAMPUS es una publicación periódica semestral, editada por la Facultad de Ingeniería y Arquitectura de la Universidad de San Martín de Porres, cuyo objetivo es servir a la divulgación y difusión del trabajo científico - tecnológico tanto nacional como internacional en las ramas de ciencias, ingeniería y arquitectura. Los artículos se publican en español, inglés y portugués.

El contenido de los artículos debe ser original e inédito y ceńirse, tanto en su formato como en su contenido a las normas de la American Psychological Association (APA), en su sexta versión en español y no pueden haber sido publicados previamente de manera parcial o total en ningún soporte ni enviado, simultáneamente, a otras revistas científicas.

Los trabajos propuestos para su publicación deben ser enviados a la dirección del Comité Editorial: Av. La Fontana 1250 Urbanización Santa Patricia, La Molina, e- mail: revistacampus@usmp.pe

Las opiniones y datos que aparecen en CAMPUS son responsabilidad de los autores. Si un trabajo es aceptado para su publicación, los derechos de impresión y reproducción por cualquier forma y medio son de la revista. El Comité Editorial de la misma se reserva el derecho de realizar modificaciones formales a los artículos para adaptar el texto a las normas de publicación.

CAMPUS no ofrece copias de los artículos publicados.

\section{DOCUMENTACIÓN OBLIGATORIA}

Es obligatorio que el autor envíe los siguientes documentos:

1. Solicitud dirigida al editor de CAMPUS, incluyendo la aceptación de condiciones de publicación; con la firma escaneada del autor principal, en representación del grupo de investigación.

2. Directorio de autores, consignando sus correos electrónicos, teléfono y contribuciones en la elaboración del artículo, según las indicaciones de la revista CAMPUS.

3. El texto debe venir acompañado de una hoja de vida breve del autor (es).

4. Artículo redactado siguiendo las pautas indicadas en las normas de publicación de la revista. Los formatos electrónicos de los documentos obligatorios se encuentran disponibles en: http://www. usmp.edu.pe/campus

5. El registro de artículos se realizará cuando se envíe correctamente la documentación obligatoria. Los artículos que no se adecúen a las normas señaladas no serán considerados para evaluación y se devolverán inmediatamente a los autores.

6. Al registrar el artículo, la revista CAMPUS le adjudicará un código de identificación único, que se usará en todo el proceso de evaluación.

\section{ESTRUCTURA DE LOS ARTÍCULOS}

Los autores deben leer estas instrucciones, en su totalidad, y revisar, al menos, un número de CAMPUS antes de presentar un artículo.

\section{ASPECTOS GENERALES}

\section{PRIMERA PÁGINA}

Debe incluir:

a. Título: en español, inglés o portu- 
gués (con una extensión máxima de 15 palabras).

b. Identificación de los autores

- Nombre y apellido de cada uno de los autores. Se mostrará solo un nombre y un apellido, o ambos apellidos unidos por un guion. En caso que los autores deseen incluir otras formas de presentación de sus nombres, deben justificarlas.

- Filiación institucional, cada autor podrá incluir como máximo dos filiaciones relevantes al artículo propuesto. Se debe incluir la ciudad y el país.

- Profesión y grado académico; cada autor debe señalar su profesión y el mayor grado académico culminado. No se aceptan términos con "candidato a", "consultor", "docente" o "profesor".

c. Fuentes de financiamiento: indicando si fue autofinanciada o financiada por alguna institución.

d. Correspondencia: indicar el nombre y apellido, dirección, teléfono y correo electrónico del autor corresponsal.

Si la investigación ha sido presentada a un congreso o forma parte de una tesis, los autores deben colocar la cita correspondiente.

\section{CUERPO DEL ARTÍCULO}

El texto debe estar redactado en Word, en tamaño de página $\mathrm{A} 4$, con formato de letra Times New Roman: 12 puntos, a doble espacio, justificados completos y en páginas numeradas en forma correlativa. La configuración de página debe ser de $3 \mathrm{~cm}$. en el margen izquierdo y $2.5 \mathrm{~cm}$. en los otros márgenes. Se debe incluir una llamada para las figuras y tablas, las mismas que se insertan en el texto, debidamente numeradas según su orden de presentación.

\section{REFERENCIAS}

Solo se incluirán las que se citan en el texto. Se usará el formato APA, de acuerdo con las normas indicadas. En el caso de existir más de seis autores, se colocará el primero seguido de et al. Asimismo, el título de la referencia deberá consignar un hipervínculo direccionado al sitio web donde se pueda tener acceso a la referencia, siempre que exista la versión electrónica correspondiente.

\section{FIGURAS Y TABLAS}

Cada tabla o figura debe adjuntarse en archivos individuales y en su formato original; en el cuerpo del artículo, debe hacerse un llamado a todas las figuras o tablas incluidas.

Figuras: se consideran figuras a los diagramas, mapas, fotografías o gráficos, los cuales deben ser ordenadas con números arábigos. Son aceptables los formatos TIFF o JGP a una resolución mayor a 800 dpi o 600 pixeles. Cada una debe tener un título breve que indique claramente su contenido.

Tablas: deben considerar la información necesaria, tanto en el contenido como en el título para poder interpretarse sin necesidad de hacer referencia al texto. Las tablas deberán presentarse en Excel y también deben ser numeradas como las figuras en orden correlativo.

Cada una debe tener un título breve que indique claramente su contenido. Los gráficos y fotos se presentarán en forma individual, fuera del texto en Word, y deben estar en formato TIFF o JGP en alta resolución. 


\section{CONSIDERACIONES DE ESTILO}

La revista utiliza el Sistema Internacional de Unidades. Los nombres científicos de las especies deben ser colocados en cursiva. En lo posible, deben evitarse abreviaturas, especialmente en el título del artículo. Si se usa debe indicarse la abreviatura entre paréntesis al momento de la primera mención. Al referirse a varios autores en el cuerpo del artículo, señalar el apellido del primer autor seguido de et al.

\section{SECCIONES DE LA REVISTA}

\section{ARTÍCULO DE INVESTIGACIÓN}

\subsection{ARTÍCULO ORIGINAL}

Son resultados de investigación que desarrollan un tema de interés para la revista, con solidez, originalidad, actualidad y de forma oportuna. Debe tener la siguiente estructura: resumen, palabras clave, introducción, materiales y métodos, resultados, discusión, conclusiones y referencias. La extensión máxima es de 250 palabras para el resumen y 28 páginas para el contenido. Debe contener un mínimo de 25 referencias.

Resumen (Abstract). Estructurado en: objetivos, materiales y métodos, resultados, y conclusiones. No debe exceder las 250 palabras, en un solo párrafo en español, inglés o portugués.

Palabras clave (key words). Debe proponerse un mínimo de tres y un máximo de siete, en español, inglés, o portugués.

Introducción. Exposición breve del estado actual del problema, antecedentes, justificación y objetivos de estudio.

Materiales y métodos. Explica la metodología usada, de modo que permita la reproducción del estudio y la evaluación de la calidad de la información.
Se describirá el tipo y diseño de la investigación y cuando sea necesario, las características de la población y forma de selección de la muestra. En algunos casos, es conveniente describir el área de estudio. También se debe mencionar los procedimientos estadísticos empleados y detallar los aspectos éticos involucrados en su realización, como la aprobación por un Comité de Ética Institucional, el uso de consentimiento informado y otras que sean pertinentes. Puede tener subtítulos para facilitar su presentación.

Resultados y discusión. Presenta los mismos de forma clara, comparándolos con los hallazgos de otros autores, exponiendo las inferencias del autor. Debe incluirse las limitaciones y posibles sesgos del estudio. Se usan tablas o figuras para aclarar las interpretaciones de los hallazgos, las cuales no deben repetir la información presentada en el texto. Es posible incluir subtítulos para facilitar su presentación

Conclusiones. Cada una se presenta en un solo párrafo. Deben estar debidamente sustentadas por los resultados obtenidos y avaladas por los análisis estadísticos efectuados.

Agradecimientos. Cuando correspon$\mathrm{da}$, debe mencionarse en forma específica a quién y por qué tipo de colaboración en la investigación se realiza el agradecimiento. Los colaboradores mencionados en esta sección deben consignar por escrito su autorización para la publicación de sus nombres.

Referencias. Todos los autores citados en el artículo deberán incluirse en esta sección.

\subsection{ARTÍCULO DE REVISIÓN}

Los artículos de revisión son publicaciones cortas que se caracterizan por pro- 
fundizar sobre un tema en particular a modo de divulgación, crítica o contribución a la comunidad académica. Se recomienda que tengan una búsqueda sistemática de la bibliografía y respondan a preguntas planteadas.

Los artículos de revisión se pueden presentar a solicitud del Comité o por iniciativa de los autores, los cuales dependiendo de la pertinencia, pasan o no por revisión por pares.

El formato de comunicación suele ser el siguiente: introducción, contenido y discusión/conclusiones.

La extensión máxima es de 250 palabras para el resumen y 20 páginas para el contenido.

\section{ESTRUCTURA DEL ARTÍCULO DE REVISIÓN}

Título del trabajo

Autor (es) e institución (es)

Resumen y Abstract

Palabras clave (Key words)

I. Introducción

II. Contenido

III. Discusión

IV. Conclusiones

V. Referencias

\subsection{COMUNICACIONES CORTAS}

Las comunicaciones cortas llamadas también: comunicación rápida, original breve, comunicación breve entre otras son producto de una investigación científica, pero por lo general son resultados preliminares que necesitan ser comunicados prontamente; por lo que estas investigaciones pueden presentar ciertas limitaciones. Estos trabajos pasan por revisión de pares. La extensión máxima es de 14 páginas para el contenido.

\section{ESTRUCTURA DE UNA COMUNI- CACIÓN CORTA}

Título del trabajo

Autor(es) e institución (es)

Resumen y Abstract

Palabras clave (Key words)

I. Introducción

II. Material y métodos

III. Resultados y discusión

IV. Conclusiones

V. Agradecimiento

VI. Referencias

\subsection{SIMPOSIO/ ENSAYO/ OPINIÓN}

Los ensayos, opiniones o simposios son publicaciones cortas y específicas, en las que el autor da cuenta de su enfoque sobre un tema de interés, por lo general a solicitud de la revista o por convocatoria de la misma. Este tipo de publicación, por lo general, marca mucho la posición del autor sobre el tema. Dependiendo del manuscrito, pasan o no por revisión de pares. La extensión máxima es de 14 páginas para el contenido.

\subsection{SECCIÓN ESPECIAL}

La sección especial incluirá artículos que se encuentren dentro de la política editorial de la revista pero que no se ajustan a las características de otras secciones. Incluye ensayos, opiniones, sistematizaciones y experiencias que sean de interés para la comunidad científica. No se aceptarán artículos que promocionen instituciones, productos, personas o que tengan conflictos de interés para su publicación. Tienen la siguiente estructu- 
ra: resumen no estructurado, palabras clave, cuerpo del artículo y referencias. La extensión máxima es de 20 páginas para el contenido y 150 palabras en el resumen.

\subsection{REPORTE DE CASOS}

Corresponde a las comunicaciones de estudios de casos de arquitectura, ingeniería, ciencias aeronáuticas, etc., en los que se describe proyectos efectuados. La extensión máxima es de 14 páginas para el contenido. Cada caso pasa por una revisión de pares.

\subsection{CARTAS AL EDITOR}

Las cartas al editor son manuscritos que pueden ser generados como respuesta a un artículo de la revista, en que se puede comunicar opiniones, sistematizaciones, investigaciones, que amplíen, profundicen, refuten o rechacen los resultados expuestos en investigaciones precedentes. Son reflejos de cuan activa es una comunidad científica y cuan leída es una revista. Estos escritos son evaluados únicamente por el Comité Editor. La extensión máxima es de cuatro páginas para el contenido.

\section{IV. ÉTICA EN PUBLICACIÓN}

La revista CAMPUS se ajusta a estándares de ética en la publicación e investigación. En el caso de que sea detectada alguna falta contra la ética en publicación durante el proceso de revisión o después de la publicación (si es que fuera el caso), la revista CAMPUS tomará las medidas necesarias.

\section{PROCESO EDITORIAL}

\subsection{EVALUACIÓN INICIAL DEL CO- MITÉ EDITOR DE LA REVISTA CAMPUS}

Los artículos registrados serán presentados y puestos a consideración del Co- mité Editor de la revista CAMPUS el cual estará conformado por un equipo multidisciplinario de expertos miembros de instituciones destacadas en investigación. El Comité Editor concluirá si el artículo corresponde a la línea editorial de CAMPUS y si requiere pasar a un proceso de revisión por pares, de lo contrario será devuelto al autor.

\subsection{SISTEMA DE ARBITRAJE}

La revisión por pares busca garantizar la calidad de los artículos que se publican. Cuando un artículo cumple con las formalidades indicadas es remitido para su evaluación en forma anónima a dos árbitros miembros del Comité Consultivo de la revista, es decir, son revisados a doble ciego (los árbitros no conocen la identidad de los articulistas y viceversa), quienes deberán comunicar en un plazo no mayor de 30 días sobre la revisión del mismo. Los evaluadores tendrán trayectoria reconocida en áreas relacionadas con el tema del artículo. La participación de los revisores es anónima y ad honorem. Ellos recibirán el manuscrito, además de una hoja de evaluación para consignar sus comentarios y recomendaciones sobre la aceptación o rechazo del artículo.

Los artículos de simposio, revisión, sección especial y reporte de casos son evaluados por uno o más revisores. Para los artículos de revisión, los revisores pueden sugerir que el artículo sea publicado como original breve o carta al editor. En función de las observaciones de los revisores, el Comité Editor decidirá la publicación del artículo, su rechazo o el envío de observaciones al autor.

Los editoriales y cartas al editor, son evaluados solo por el Comité Editor de la revista CAMPUS, salvo casos en que, por acuerdo, se requiera la participación de un revisor externo. 
Los artículos tienen tres modalidades de evaluación:

- Está listo para su publicación.

- Han de realizarse algunas modificaciones.

- No se recomienda su publicación.

Si el informe de los evaluadores es positivo seguirá el proceso de publicación correspondiente de acuerdo a las normas establecidas por la revista CAMPUS. En caso de ser negativo el resultado de la evaluación deberá recoger su trabajo en un plazo no mayor de quince días calendarios, transcurridos los cuales el Instituto de Investigación no se hará responsable por el material.

\subsection{RESPUESTA A OBSERVACIONES}

El autor debe enviar el artículo corregido y, en un documento aparte, la respuesta a cada una de las observaciones enviadas. Tiene un plazo máximo de treinta días para responder.

Las observaciones por parte de los revisores y del Comité Editor de CAMPUS deberán ser resueltas satisfactoriamente a criterio del Comité Editor para que este decida la publicación del artículo. CAMPUS podrá volver a enviar el artículo corregido a un revisor antes de considerar su publicación.

El tiempo promedio del proceso editorial, que incluye desde la recepción del artículo hasta la decisión final del Comité Editor de revista, varía entre dos a cuatro meses, dependiendo de la celeridad de nuestros revisores y la respuesta de los autores.

\subsection{PRUEBAS DE IMPRENTA}

Los artículos aprobados pasarán al proceso final de edición, donde se pueden realizar modificaciones que sean necesarias, en reducciones o ampliaciones presentadas a los autores para la aprobación final de la prueba de imprenta (en formato PDF). Los cambios a este nivel serán en aspectos formales y no de contenido. En caso los autores no realicen observaciones a la prueba de imprenta, CAMPUS dará por aceptada la versión final.

CAMPUS solo publicará los artículos que hayan cumplido con todas las etapas del proceso y recibido el visto favorable para su publicación por el Comité Editor.

\section{COMUNICACIÓN GENERAL}

Se recomienda a los autores tener en cuenta los siguientes aspectos para el seguimiento de sus artículos enviados a la revista CAMPUS.

- Realizar un acuse de recibo ante cada comunicación. Se enviará una copia de la carta de recepción y de la prueba de imprenta a cada uno de los autores de cada artículo.

- El autor corresponsal del artículo puede consultar en cualquier momento sobre los avances de la revisión de su artículo, para ello debe considerar los tiempos de revisión señalados en el "Proceso editorial".

- En caso de que no se reciba una respuesta a las observaciones que se envíen en las siguientes ocho semanas de enviada la comunicación, el artículo será retirado del proceso editorial.

- Ante cualquier duda, puede consultarnos al siguiente correo electrónicorevistacampus@usmp.pe o llamarnos a estos números +511 2086000 anexo 1146 - 2086012. 